\title{
ASPECTS OF CYCLON AND BDNF GENE EXPRESSION IN SCHIZOPHRENIA PATIENTS
}

\author{
Trifon Chervenkov ${ }^{1}$, Rinaldo Shishkov ${ }^{2}$. \\ 1) Department Clinical Medical Sciences, Immunology laboratory, \\ 2) Department Psychiatry and Medical Psychology, \\ Medical University - Varna, Bulgaria,
}

\begin{abstract}
:
The pathogenesis of the schizophrenic illness is still not fully elucidated. Many studies have been conducted revealing different aspects but may be the studies of greatest significance are studying the genetic aspects of expression of trophic factors and enzymes associated with nervous system development and plasticity. In this relation we aimed at measuring the Cyclon and BDNF genes expression in blood of patients suffering from schizophrenia and to test for correlation between them. Our result did not reveal correlation in spite of their connection with the disease.
\end{abstract}

Key words: schizophrenia, $c c d c 86$, Cyclon, BDNF

The pathogenesis of the schizophrenic illness is still not fully elucidated. In this relation many studies have been performed examining the function of different systems in the organism. One of these directions is associated with the activity of the immune system and its effects on neural plasticity, glial activation and eventually the associated functional disorders of CNS. In this regard several studies for genetic associations with schizophrenia a linkage is found with components of the IL-3 signaling pathway - the gene coding for IL-3 (3) and the genes coding for the two subunits of the IL-3 receptor $(4,11)$

In 2008 Akemi Hoshino и Hodaka Fujii(10) identified the gene CCDC86 to be directly induced by IL-3 in a IL-3 dependent pro-B cell line (14 ) and named it Cyclon (cytokine induced protein with coiled-coil domain)(10). In a consequent study the gene was identified to be important for the phenomenon of activation induced cell death (AICD) in T lymphocytes (14). The transgenic overexpression of Cyclon enhances the activation-induced cell death of CD4+ and CD8+ $\mathrm{T}$ lymphocytes and targeted deletion of Cyclon allele leads to resistance to AICD and lower expression of Fas (CD95) (14). These experiments demonstrate that Cyclon modulates the activation induced cell death and that this effect is mediated through induction of the expression of the cell membrane pro-apoptic death receptor Fas. This receptor is a member of the Tumor Necrosis Factor Receptor Superfamily, member 6 , and plays pivotal role in regulation of programmed cell death and the proper physiological functioning of the immune system (19). Cyclon is also expressed in the central nervous system - in neurons and glia, and probably in these cells it also regulates the Fas expression and hence the process of programmed cell death. Neuronal and glial apoptosis are processes definitely associated with the pathogenesis of the disease and therefore it is possible that Cyclon also plays important role in the pathogenesis of schizophrenia.

Another factor associated with the cell differentiation and apoptosis of cells in the nervous system is BDNF. Concerning the genetic link of BDNF with the pathogenesis of schizophrenia of interest is a study of Agartz et al. (1). The authors found an association between a polymorphism of BDNF and brain morphology in patient with schizophrenia. In a MRI study of the volume of cerebellar tonsils, hemispheres and subregions of vermis, striatal structures, hippocampus and corpus callosum differences between patients and healthy controls were found. A significant difference in the volume of frontal gray matter is associated with BDNF $11757 \mathrm{G} / \mathrm{C}$ polymorphism, and $270 \mathrm{C} / \mathrm{T}$ polymorphism is associated with caudate nucleus total volume (1). In other studies a link between BDNF gene and neural development displayed as a modulation of activity dependent synaptic plasticity in differentiating neurons, particularly in the hippocampal region and neocortex were found $(7,12,18)$.

There are studies indicating that the rs6265 methionine/ valine single nucleotide polymorphism (SNP) is associated with memory alterations $(5,6,9,16)$. Moreover, in previous cross-sectional MRI studies the presence of methionine allele is associated with lower volume of frontal and temporal gray matter compared to the volume in valine homozygotes $(1,9$, 17).

Many evidences point towards the genetic link between the neurotrophins and schizophrenia. Role in the pathogenesis of schizophrenia also play other neurotrophins besides BDNF and its allelic variants. Neurotrophins like NT3 and its polymorphisms are probably also connected to schizophrenia $(4,8)$. Later observations show that the level of expression of BDNF is lowered even before the first 
schizophrenic episode and correlates with stress (15) and estrogen level (13). These observations are in unison with many hypotheses about schizophrenia which view biochemical and genetic factors as key entities in disease pathogenesis and are associated with BDNF (2).

Considering all these observations our aim was to assess the mRNA expression of Cyclon and the level of BDNF in peripheral blood in patients suffering from schizophrenia.

\section{PATIENTS:}

16 patients were recruited to the study, 4 male with average age 28,3 years and 12 female with average age 38,2 years. The patients were sampled twice - during disease relapse and after at least 21 days after accomplishing a drug induced remission. The patients were on standard treatment with second generation antipsychotics.

\section{METHODS:}

Expression of Cyclon mRNA in peripheral blood leucocytes. $6 \mathrm{ml}$ of anticoagulated venous blood was collected in K2 EDTA vacuum closed system. Total RNA isolation from blood leukocytes was performed with QIAamp RNA Blood Mini Kit (QIAGEN, Germany) according to manufacturer's instructions and stored at $-80^{\circ} \mathrm{C}$ until further analysis. Reverse transctiption of total RNA to cDNA was performed with Precision ${ }^{\mathrm{TM}}$ Reverse Transcription Kit (PrimerDesign, United Kingdom) with random nonamer primers according to manufacturer's instructions. Quantitative polymerase chain reaction was performed with SYBR Green Precision $^{\mathrm{TM}}$ 2X Real-Time qPCR MasterMix (PrimerDesign, United Kingdom) and gene specific primers for the target gene $C C D C 86$ and the $A C T B$ reference gene (PrimerDesign, United Kingdom) according to manufacturer's instructions. qPCR was performed on StepOne Plus (Applied Biosystems, USA). The relative expression of the CCDC86 target gene mRNA compared to reference gene $A C T B$ mRNA was calculated using $\Delta \Delta \mathrm{Ct}$ method by the instrument software (StepOne Software v2.0) and presented as ratio to a reference sample.

Plasma BDNF. $6 \mathrm{ml}$ of anticoagulated venous blood was collected in K2 EDTA vacuum closed system. The sample was transported on ice $\left(4^{\circ} \mathrm{C}\right)$ in less than 30 minutes and blood plasma was separated after centrifugation at $1000 \mathrm{x} \mathrm{g}$ for 15 minutes at $\left(4^{\circ} \mathrm{C}\right)$. The separated blood plasma was stored at $-80^{\circ} \mathrm{C}$ until further analysis. Plasma BDNF was quantified using Quantikine Human BDNF Immunoassay ELISA Kit, catalog number DBD00 (R\&D Systems, USA) according to manufacturer's instructions.

Statistical analysis: t-test and correlation analysis.

\section{RESULTS:}

The relative expression of $C y c l o n / C C D C 86$ in relapse and remission are shown in fig. 1. The results show statistically significant difference (higher in relapse) in the expression between relapse and remission in schizophrenia patients (t-test, $\mathrm{P}<0,01$ ).

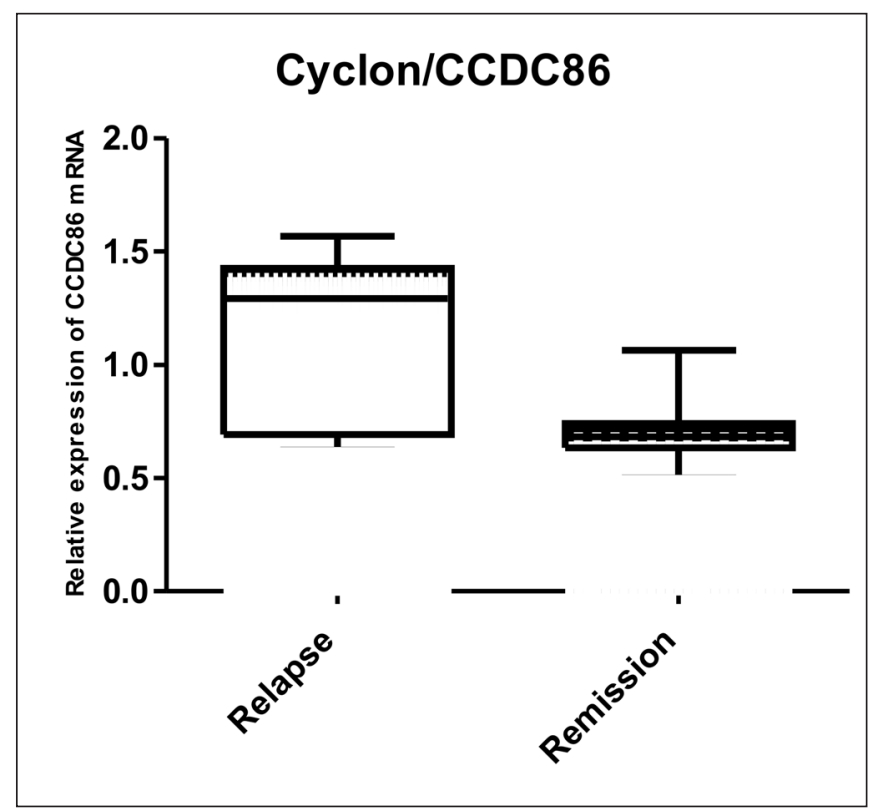

Fig. 1. Relative expression of Cyclon/CCDC86 mRNA in relapse and remission of schizophrenia.

The plasma levels of BDNF in relapse and remission are shown in fig. 2. There is trend for higher level of BDNF in remission compared to BDNF in relapse, but the difference is not statistically significant.

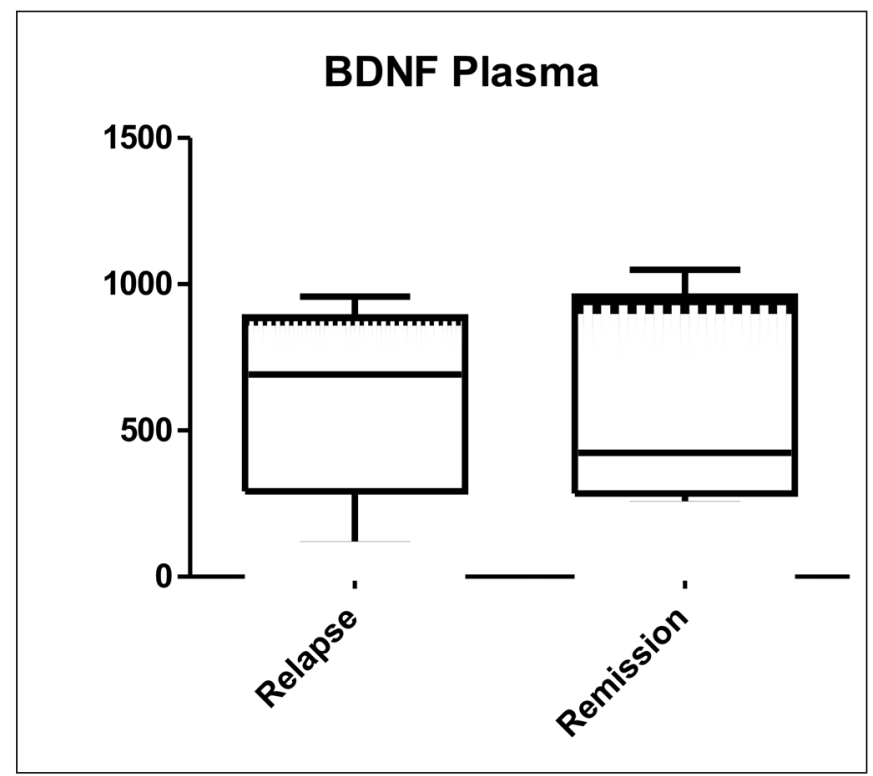

Fig. 2. Plasma level of BDNF in relapse and remission of schizophrenia. 
We did not find correlation between Cyclon mRNA and plasma BDNF level in relapse $(\mathrm{r}=0,154, \mathrm{P}=0,691)$ and in remission ( $\mathrm{r}=0,107, \mathrm{P}=0,818)$.

\section{DISCUSSION:}

Considering the multitude of different theories trying to explain the pathogenesis of schizophrenia and the many unclarities we sought to assess the dynamics of Cyclon gene mRNA in peripheral blood leukocytes. To our knowledge there is no data in the literature. Because Cyclon is induced by IL-3 and there are many studies linking IL-3 and schizophrenia we propose that Cyclon may be involved in the pathogenesis of schizophrenia. Our result show dynamics, i.e. statistically significant difference in the expression between period of relapse and remission.

Concerning the levels of BDNF in blood plasma the concentration is higher in remission compared to relapse but the difference is not statistically significant.
The results show dynamics in the parameters tested but without proven correlation between Cyclon and BDNF in relapse and remission.

According to the data for the role of BDNF in the processes of apoptosis and neuronal plasticity and the processes of neuroinflammation (1) and the link between IL3 and Cyclon (15) probably both play important role in the pathogenesis of schizophrenia and their effects on apoptosis, plasticity and glial mediated inflammation are synergistic(1).

As for BDNF there are many confirmations for its link with schizophrenia in literature for Cyclon the data is scarce and these are first reports for its link with schizophrenia. Cyclon is involved with immune system regulation and autoimmunity and its link with schizophrenia is point for a long considered hypothesis - that schizophrenia is in fact an autoimmune disease.

\section{REFERENCES:}

1. Agartz I, Sedvall GC, Terenius L, Kulle B, Frigessi A, Hall H, et al. BDNF gene variants and brain morphology in schizophrenia. Am J Med Genet B Neuropsychiatr Genet. 2006 Jul 5; 141B(5):513-523. [PubMed] [CrossRef]

2. Angelucci F, Brene S, Mathe AA. BDNF in schizophrenia, depression and corresponding animal models $\mathrm{Mol}$ Psychiatry. 2005 Apr;10(4):345-352. [PubMed] [CrossRef]

3. Chen X, Wang X, Hossain S, O'Neill FA, Walsh D, van den Oord E, et al. Interleukin 3 and schizophrenia: the impact of sex and family history. Mol Psychiatry. 2007 Mar;12(3):273-82. [PubMed] [CrossRef]

4. Chen Q, Wang X, O'Neill FA, Walsh D, Fanous A, Kendler KS, et al. Association study of CSF2RB with schizophrenia in Irish family and case - control samples. Mol Psychiatry. 2008 Oct;13(10):930-8. [PubMed] [CrossRef]

5. Dempster E, Toulopoulou T, McDonald C, Bramon E, Walshe M, Filbey F, et al. Association between BDNF val66 met genotype and episodic memory. Am J Med Genet B Neuropsychiatr Genet. 2005; Apr 5; 134B(1): 73-75. [PubMed] [CrossRef]

6. Egan MF, Kojima M, Callicott JH,
Goldberg TE, Kolachana BS, Bertolino A, et al. The BDNF val66met polymorphism affects activity dependent secretion of BDNF and human memory and hippocampal function. Cell. 2003 Jan 24;112(2):257269. [PubMed] [CrossRef]

7. Gorski JA, Zeiler SR, Tamowski S, Jones KR. Brain - derived neurotrop hic factor is required for the maintenance of cortical dendrites. $J$ Neurosci. 2003 Jul 30;23(17):6856-6865. [PubMed]

8. Hattori M, Kunugi H, Akahane A, Tanaka H, Ishida S, Hirose T, et al. Novel polymorphisms in the promoter region of the neurotrophin - 3 gene and their associations with schizophrenia. Am $J$ Med Genet. 2002 Apr 8;114(3):304-309. [PubMed] [CrossRef]

9. Ho BC, Milev P, O'Leary DS, Librant A, Andreasen NC, Wassink TH: Cognitive and magnetic resonance imaging brain morphometric correlates of brain - derived neurotrophic factor Val66Met gene polymorphism in patients with schizophrenia and healthy volunteers. Arch Gen Psychiatry. 2006 Jul;63(7):731-740. [PubMed]

10. Hoshino A, Fujii H. Redundant promoter elements mediate IL-3induced expression of a novel cytokine-inducible gene, cyclon. FEBS Lett. 2007 March 6; 581(5):975-980. [PubMed] [CrossRef]

11. Lencz T, Morgan TV, Athanasiou M, Dain B, Reed CR, Kane $\mathrm{JM}$, et al. Converging evidence for a pseudoautosomal cytokine receptor gene locus in schizophrenia. Mol Psychiatry. 2007 Jun;12(6):572-80. [PubMed] [CrossRef]

12. Lu B. BDNF and activity dependent synaptic modulation. Learn Mem. 2003 Mar-Apr;10(2):86-98. [PubMed] [CrossRef]

13. Singh M, Meyer EM, Simpkins JW. The effect of ovariectomy and estradiol replacement on brain - derived neurotrophic factor messenger ribonucleic acid expression in cortical and hippocampal brain regions of female Sprague Dawley rats. Endocrinology 1995 May 1;136(5): 2320-2324. [PubMed] [CrossRef]

14. Saint Fleur S, Hoshino A, Kondo K, Egawa T, Fujii H. Regulation of Fas-mediated immune homeostasis by an activation-induced protein, Cyclon. Blood. 2009 Aug 13; 114(7): 1355-65. [PubMed] [CrossRef]

15. Smith MA, Makino S, Kvetnansky R, Post RM. Stress and glucocorticoids affect the expression of 
brain - derived neurotrophic factor and neurotrophin - 3 mRNAs in the hippocampus. $J \quad$ Neurosci 1995 Mar;15(3 Pt 1):1768 1777. [PubMed]

16. Szekeres G, Juhasz A, Rimanoczy A, Keri S, Janka Z. The C270T polymorphism of the brain derived neurotrophic factor gene is associated with schizophrenia. Schizophr Res. 2003 Dec 1;65(1):15-
18. [PubMed] [CrossRef]

17. Szeszko PR, Lipsky R, Mentschel C, Robinson D, GunduzBruce H, Sevy S, et al. Brain-derived neurotrophic factor Val66met polymorphism and volume of the hippocampal formation. Mol Psychiatry. 2005 Jul;10(7):631-636. [PubMed] [CrossRef]

18. Xu B, Zang K, Ruff NL, Zhang
YA, McConnell SK, Stryker MP, et al. Cortical degeneration in the absence of neurotrophin signaling: dendritic retraction and neuronal loss after removal of the receptor TrkB. Neuron. 2000 Apr;26(1):233-245. [PubMed] [CrossRef]

19. http://en.wikipedia.org/wiki/ CD95

\section{Corresponding author:}

Trifon Chervenkov, MD

Department Clinical Medical Sciences, Immunology laboratory, Medical University of Varna

1, Hr. Smirnenski Blvd., 9010 Varna, Bulgaria

E-mail: tuckata@gmail.com 